\title{
Use of 2D and multislice transperineal ultrasonography to describe the degree of perineal laceration following vaginal delivery
}

\author{
Budi I. Santoso, Suskhan Djusad, Surahman Hakim, Fernandi Moegni, Alfa P. Meutia, Tyas Priyatini
}

Department of Obstetrics and Gynecology, Faculty of Medicine Universitas Indonesia, Cipto Mangunkusumo Hospital, Jakarta, Indonesia

\section{ABSTRACT}

Background: Perineal tear is the most common complication after vaginal delivery. Pill-rolling test is a widely used clinical evaluation method to determine the degree of perineal tear. However, the evaluation results of anal sphincter complex (ASC) differ between clinical examination and 2D/multislice transperineal ultrasonography (TPUS). This study aims to describe measurement variation between these modalities.

Methods: This cross-sectional study was conducted at Cipto Mangunkusumo Hospital from November 2015 to May 2016. Subjects were primiparous women after vaginal delivery. Clinical examination using pill-rolling test was performed to determine the degree of perineal laceration. Suture was conducted accordingly. The subjects were subjected to 2D/multislice TPUS 72 hours after delivery to evaluate the integrity of internal and external anal sphincters. Data were collected and analyzed to determine compatibility between these examinations.

Results: Among 70 prospective primiparous women, five were excluded due to unavailability to undergo 2D/multislice TPUS 72 hours after delivery. The mean duration to perform 2D/multislice TPUS was 4.5 minutes, and pain was tolerable during the examination. The compatibility values of clinical examination with $2 \mathrm{D}$ and multislice TPUS were 0.98 and 0.93 , respectively, with Cohen's kappa of 0.92 (95\% CI 0.81-1.00) and 0.79 (95\% CI 0.58-0.99), respectively.

Conclusion: Clinical examination is compatible with 2D/multislice TPUS for determining the degree of perineal tear after vaginal delivery.

Keywords: 2D or multislice transperineal ultrasonography, perineal laceration, pill-rolling test, vaginal delivery

pISSN: 0853-1773•eISSN: 2252-8083・https://doi.org/10.13181/mji.v27i2.1908• Med J Indones. 2018;27:108-13

- Received 14 Mar 2017 • Accepted 6 May 2018

Corresponding author: Tyas Priyantini

tyasprytn@gmail.com

Copyright @ 2018 Authors. This is an open access article distributed under the terms of the Creative Commons Attribution-NonCommercial 4.0 International License (http://creativecommons.org/licenses/by-nc/4.0/), which permits unrestricted non-commercial use, distribution, and reproduction in any medium, provided the original author and source are properly cited. 
Women may experience anatomical changes in the anal sphincter after vaginal or cesarean delivery. ${ }^{1,2}$ Perineal tear is the most common complication after vaginal delivery. A prospective study showed that the prevalence of occult obstetric anal sphincter injuries (OASIS) is $20-41 \%$. About $85 \%$ of women had perineal tear during vaginal delivery, ${ }^{4}$ and $0.6-36 \%$ of the population experienced anal sphincter injury due to labor process. ${ }^{5}$ Therefore, accurate and acceptable imaging options must be developed for evaluating the anal sphincter complex (ASC). At present, pillrolling test is a widely used clinical evaluation method to determine the degree of laceration on perineum. The ASC evaluation result may differ between clinical examination and 2D/multislice transperineal ultrasonography (TPUS).

Several methods can be used to assess perineal laceration and determine anal sphincter injury; these methods include clinical examination of the vagina and rectum (pillrolling test), magnetic resonance imaging (MRI), and ultrasonography (US). Previous studies suggested endoanal ultrasonography (EAUS) as the "reference standard" for evaluating the ASC. ${ }^{6,7}$ Misidentification and misclassification of the degree of perineal tear will cause complications, including flatus and fecal incontinence, voiding dysfunction, sexual dysfunction, perineal pain, and rectovaginal fistula. ${ }^{8}$ However, recent studies indicated that the ASC can be reproducibly evaluated with TPUS. ${ }^{7,9}$ Although TPUS is widely used to accurately detect anal sphincter defects, clinical assessment still plays an important role in diagnosis and determination of future management procedures.

To date, no study has compared the compatibility of clinical examination with 2D/ multislice TPUS for determining the degree of perineal tear of women after vaginal delivery in Indonesia. This study aims to assess the agreement between clinical examination and 2D/multislice TPUS in determining the degree of perineal tear after vaginal delivery.

\section{METHODS}

This cross-sectional study employed consecutive sampling design and given ethical approval (No.1120/UN2.F1/ETIK/2015) by the Ethical Committee of Cipto Mangunkusumo Hospital. The study was conducted at Obstetrics and Gynecology Department of Cipto Mangunkusumo Hospital in Jakarta from November 2015 to May 2016. Data were prospectively collected from clinical examination and 2D/multislice TPUS.

Primiparous women after vaginal delivery (18-40 years old) were recruited. The exclusion criteria were as follows: history of anal/perineal surgery, inability to perform TPUS, and inconclusive TPUS result. Labor and delivery information, patient characteristics, and data on perineal laceration were obtained. Women with second-degree laceration were evaluated by a second examiner. Third- and fourth-degree lacerations were repaired at delivery by using standard methods. Clinical examination was performed using the standard pill-rolling test. By palpation, the examiner simultaneously inserted the index finger into the anus and the thumb in the vaginal canal and applied pill-rolling movement to evaluate the thickness and integrity of the perineal tissue. Women detected with anal sphincter defect was subjected to a standard repair methodology, which included identification and repair of internal anal sphincter (IAS) by using PGA 3.0 suture in horizontal mattress manner and repair of external anal sphincter (EAS) by using PGA 2.0 suture in an end-to-end or overlapping manner depending on the degree of perineal laceration. ${ }^{10-12}$

All patients underwent 2D/multislice TPUS 72 hours after delivery, and the sonographer was unaware of the patient's mode of delivery and the degree of perineal laceration. All 2D/multislice TPUS volume sets were acquired using GE Voluson E8 expert BT09 (GE Medical System, Zipf, Austria) with 4-9 MHz convex volume probe RIC5-9-D. The probe was placed horizontally on the perineum, and the angle was modified to obtain the transversal plane image of the anal sphincter. The anal sphincter structure was evaluated at rest and during contraction in 2D mode. Defect of anal sphincter was defined as discontinuity in the sphincter at a specific location (Figure 1). Laceration degree was classified based on Sultan criteria; ${ }^{13}$ IIIA-IIIB if discontinuity is detected in the EAS, and IIIC if discontinuity appears in the IAS. In 3D mode, the area of interest was focused on the anal sphincter structure including midsagittal and transversal 
Table 1. Characteristics of subjects

\begin{tabular}{|c|c|}
\hline Variables & $\begin{array}{l}\text { Frequency, } n(\%) \\
\qquad(n=65)\end{array}$ \\
\hline Age (year) & $22.5(15-39)$ \\
\hline \multicolumn{2}{|l|}{ Vaginal delivery } \\
\hline Spontaneous & $55(84.5 \%)$ \\
\hline Bracht maneuver & $1(1.5 \%)$ \\
\hline Vacuum & $8(12.3 \%)$ \\
\hline Forceps & $1(1.5 \%)$ \\
\hline Birth weight (grams) & $2,485(550-3,620)$ \\
\hline Second phase (minutes) & $15(5-90)$ \\
\hline \multicolumn{2}{|l|}{ Episiotomy } \\
\hline Mediolateral & $20(30.8 \%)$ \\
\hline Not performed & $45(69.2 \%)$ \\
\hline \multicolumn{2}{|l|}{ Perineal tear } \\
\hline \multicolumn{2}{|l|}{ Clinical examination } \\
\hline Non OASIS & $60(92.2 \%)$ \\
\hline Intact & $6(9.2 \%)$ \\
\hline I degree & $9(13.8 \%)$ \\
\hline II degree & $45(69.2 \%)$ \\
\hline IIIA degree & $3(4.6 \%)$ \\
\hline IIIB degree & $2(3.1 \%)$ \\
\hline IIIC degree & $0(0 \%)$ \\
\hline IV degree & $0(0 \%)$ \\
\hline \multicolumn{2}{|l|}{ 2D TPUS^ } \\
\hline Non OASIS & $60(92.2 \%)$ \\
\hline OASIS & $5(7.8 \%)$ \\
\hline \multicolumn{2}{|l|}{ Multi slice TPUS^^} \\
\hline Non OASIS & $60(92.2 \%)$ \\
\hline IIIA degree & $0(0 \%)$ \\
\hline IIIB degree & $4(6.2 \%)$ \\
\hline IIIC degree & $1(1.6 \%)$ \\
\hline IV degree & $0(0 \%)$ \\
\hline
\end{tabular}

planes. The angle was manipulated until the IAS and EAS were clearly and completely shown and planes. The angle was manipulated until the IAS and EAS were clearly and completely shown and the fascial plane was identified. The fascial plane is important to be included because it shows the proximal border of the anal sphincter. The 3D mode was changed into tomographic ultrasound imaging with slice intervals of 1.0-2.5 mm. Defect of anal sphincter was defined as discontinuity in the sphincter at a specific location. Laceration degree was classified as IIIA if discontinuity is detected in $\leq 3$ out of 6 slices of EAS, IIIB if discontinuity is detected in $\geq 4$ out of 6 slices of EAS, and IIIC if discontinuity also appears in the IAS (Figure 2). The condition of postpartum tissue and the appearance of the suture material on the US image may affect TPUS analysis. For the first 24 hours, the tissue tends to be more edematous and produce an unclear US image. For more than 72 hours, the wound healing process complicates the detection of the actual gap or discontinuity of the anal sphincter. ${ }^{14,15}$ Therefore, evaluation was conducted 24-72 hours after delivery.

\section{RESULTS}

Among 70 primiparous women who underwent vaginal delivery from November 2015 to May 2016 at Cipto Mangukusumo Hospital in Jakarta, 65 were included in the analysis. Five subjects were excluded because they did not undergo TPUS.

Table 1 lists the characteristics of subjects recruited in the study. The mean examination time was 4.5 minutes, and the mean

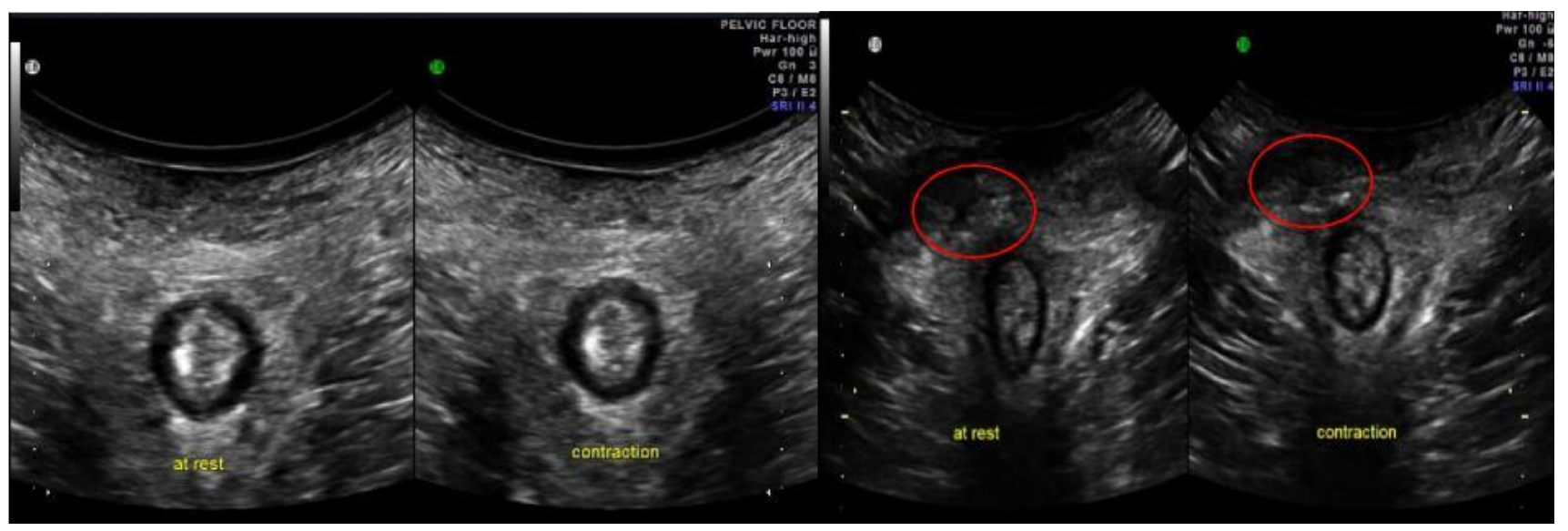

Figure 1. Result of 2D TPUS showing intact anal sphincter (right) and defect on external anal sphincter (left) 


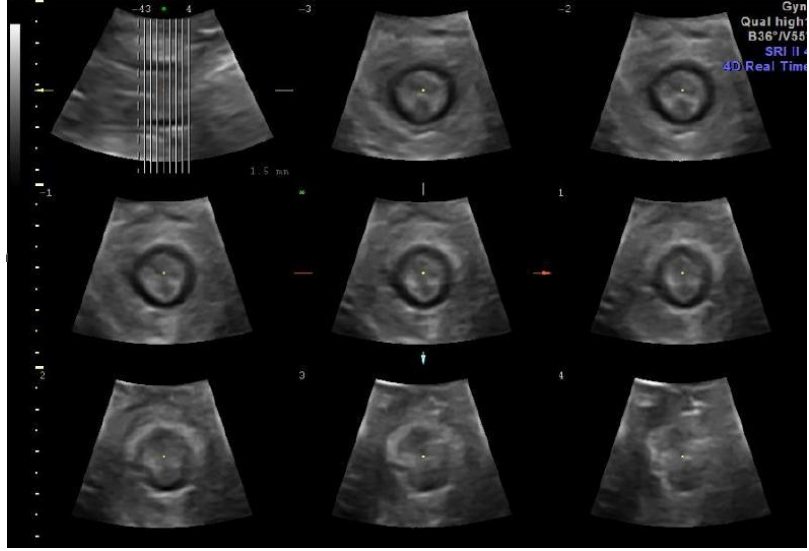

Figure 2. Result of multislice TPUS showing complete image from proximal to distal of anal sphincter. No discontinuity was noted

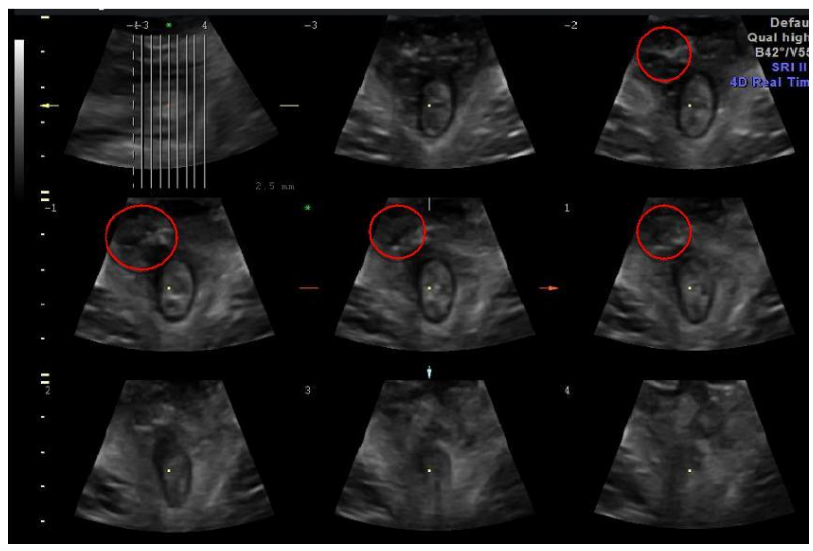

Figure 3. Result of multislice TPUS with slice interval of $2.5 \mathrm{~mm}$. EAS discontinuity was noted in four out of six slices (red circle)
0.92; 95\% CI 0.81-1.00) and 0.93 (Cohen's Kappa 0.79; 95\% CI 0.58-0.99), respectively (Table 2).

\section{DISCUSSION}

EAUS has long been referred to as the "reference standard" for evaluation of the anal sphincter. This technique is comparable with MRI and has advantages in imaging certain planes. ${ }^{16}$ However, other studies indicated that TPUS can also be used to examine dynamic changes in the anal sphincter with notable reliability. ${ }^{17}$ The presentstudyaims to comparethestandard clinical examination used in practice and 2D/multislice TPUS as reference method; US can clearly assess the perineal structure and is cheaper and more easily available than MRI.,18 The results showed that TPUS performed immediately within 24-72 hours postpartum is generally acceptable (the mean duration of examination is 4.5 minutes) and the pain was tolerable. ${ }^{9}$ Assessment within 24-72 hours postpartum led to good compatibility for describing perineal tear to labor time. Before 72 hours, no bridging structure was found among the tear so we can still identify the gap structure even after perineorrhaphy.

Sultan et $\mathrm{al}^{8}$ found that $33 \%$ women had undetected occult OASIS on delivery. Another prospective study indicated that the prevalence of occult OASIS was $20-41 \% .^{3}$ An important

Table 2. Results of clinical examination and 2D/multislice TPUS in assessing the degree perineal laceration after vaginal delivery

\begin{tabular}{|c|c|c|c|c|c|c|c|c|c|c|}
\hline & & \multicolumn{4}{|c|}{ OASIS B* } & \multicolumn{5}{|c|}{ OASIS } \\
\hline & & \multicolumn{4}{|c|}{ TPUS 2D } & \multicolumn{5}{|c|}{ TPUS multislice } \\
\hline & & Non & IIIA & IIIC & IV & Non & IIIA & IIIB & IIIC & IV \\
\hline \multirow[t]{5}{*}{ Clinical examination } & Non OASIS & 60 & - & - & - & 60 & - & - & - & - \\
\hline & IIIa & - & 4 & 1 & - & - & - & 3 & - & - \\
\hline & IIIb & & & & & - & - & 1 & 1 & - \\
\hline & IIIc & - & - & - & - & - & - & - & - & - \\
\hline & IV & & & & & - & - & - & - & - \\
\hline
\end{tabular}

*Can not be differentiated by 2D TPUS

time between delivery and TPUS was 41 hours. The compatibility values of the clinical examination results with the findings of 2D TPUS and multislice TPUS were 0.98 (Cohen's Kappa consideration is a confirmation whether the defect is truly occult, misdiagnosed, or misclassified. Sultan stated that misclassification could be due to lack of knowledge and training on identification of 
third-degree perineal tear (OASIS) among general practitioners and midwives. ${ }^{11}$ In the present study, we did not detect occult OASIS. We concluded that regular training provided to our doctors makes them competent in determining the degree of perineal tear and in performing repair/suture accordingly.

This study only included primiparous women to avoid misinterpretation of the US image due to prior delivery. The other limitation of this study was the discrepancy between the overall result and in OASIS cases only. The overall result showed good compatibility between clinical examination and 2D/multislice TPUS in determining the degree of perineal tear after vaginal delivery. However, the result among OASIS cases only failed to show similar conclusion. Considering that only five subjects were detected with OASIS during the study period, we must conduct further research on OASIS cases only. This study is the first to compare clinical examination and 2D/multislice TPUS for determining the degree of perineal tear after vaginal delivery by using Sultan classification. Many studies performed 2D/multislice TPUS to evaluate the anal sphincter anatomy 3-6 months postpartum. In the present study, we performed TPUS immediately 24-72 hours postpartum. The novelty of this study lies on the use of Sultan classification and timing for TPUS.

In conclusion, 2D/multislice TPUS is compatible with clinical examination for assessing the degree of perineal tear after vaginal delivery. However, discrepancy was noted between the overall results and that of the OASIS group only. Hence, further research must be conducted on OASIS cases.

\section{Conflict of interest}

The authors affirm no conflict of interest in this study.

\section{Acknowledgment}

Thank you to all Obstetrics Gynecology residents for supporting this research from recruiting participants and collecting data.

\section{REFERENCES}

1. Meriwether KV, Hall RJ, Leeman LM, Migliaccio L, Qualls C, Rogers RG. Anal sphincter complex: 2D and 3D endoanal and translabial ultrasound measurement variation in normal postpartum measurements. Int Urogynecol J. 2015;26(4):511-7.

2. Meriwether KV, Hall RJ, Leeman LM, Migliaccio L, Qualls C, Rogers RG. Postpartum translabial 2D and 3D ultrasound measurements of the anal sphincter complex in primiparous women delivering by vaginal birth versus cesarean delivery. Int Urogynecol J. 2014;25(3):329-36.

3. Rieger N, Schloithe A, Saccone G, Wattchow D. A prospective study of anal sphincter injury due to childbirth. Scand J Gastroenterol. 1998;33(9):950-5.

4. McCandlish R, Bowler U, van Asten H, Berridge G, Winter $\mathrm{C}$, Sames L, et al. A randomised controlled trial of care of the perineum during second stage of normal labour. $\mathrm{Br} \mathrm{J}$ Obstet Gynaecol. 1998;105(12):1262-72.

5. Christianson LM, Bovbjerg VE, McDavitt EC, Hullfish KL. Risk factors for perineal injury during delivery. Am J Obstet Gynecol. 2003;189(1):255-60.

6. Roos AM, Abdool Z, Sultan AH, Thakar R. The diagnostic accuracy of endovaginal and transperineal ultrasound for detecting anal sphincter defects: the PREDICT study. Clin Radiol. 2011; 66(7):597-604.

7. Abdool Z, Sultan AH, Thakar R. Ultrasound imaging of the anal sphincter complex: a review. Br J Radiol. 2012; 85(1015):865-75.

8. Sultan AH, Kamm MA, Hudson CN, Thomas JM, Bartram CI. Anal-sphincter disruption during vaginal delivery. N Engl J Med. 1993;329(26):1905-11.

9. Valsky DV, Messing B, Petkova R, Savchev S, Rosenak D, Hochner-Celnikier D, et al. Postpartum evaluation of the anal sphincter by transperineal three-dimensional ultrasound in primiparous women after vaginal delivery and following surgical repair of third-degree tears by the overlapping technique. Ultrasound Obstet Gynecol. 2007;29(2):195-204.

10. Fernando RJ, Sultan AH, Kettle C, Thakar R. Methods of repair for obstetric anal sphincter injury. Cochrane Database Syst Rev. 2013;8(12):CD002866.

11. Dickinson KJ, Pickersgill P, Anwar S. Functional and physiological outcomes following repair of obstetrics anal sphincter injury. A case. Int J Surg. 2013;11(10):1137-40.

12. van Roon Y, Kirwin C, Rahman N, Vinayakarao L, Melson L, Kester N, et al. Comparison of obstetric anal sphincter injuries in nulliparous women before and after EPISCISSORS- $60^{\circledR}$ at two hospitals in the United Kingdom. Int J Womens Health. 2015;7:949-55.

13. Sultan AH, Ranee T, Fenner DE. Diagnosis of perineal trauma. In: Perineal and Anal Sphincter Trauma: Diagnosis and Clinical Management. London: SpringerVerlag; 2007. p. 13-9.

14. Thiruvoth FM, Mohapatra DP, Sivakumar DK, Chittoria RK, Nandhagopal V. Current concepts in the physiology of adult wound healing. Plast Aesthet Res. 2015;2(5):250-6.

15. Shek KL, Guzman-Rojas R, Dietz HP. Residual defects of the external anal sphincter following primary repair: an observational study using transperineal ultrasound. Ultrasound Obstet Gynecol. 2014;44(6):704-9.

16. Dietz HP. Pelvic floor ultrasound: a review. Am J Obstet Gynecol. 2010;202(4):321-34.

17. Weinstein MM, Pretorius DH, Jung SA, Nager CW, Mittal 
RK. Transperineal three-dimensional ultrasound imaging for detection of anatomic defects in the anal sphincter complex muscles. Clin Gastroenterol Hepatol. 2009;7(2):205-11.
18. Wieczorek AP, Stankiewicz A, Santoro GA, Woźniak MM Bogusiewicz M, Rechberger T. Pelvic floor disorders: role of new ultrasonographic techniques. World J Urol. 2011;29(5):615-23. 